\begin{tabular}{|c|c}
$\begin{array}{c}\text { Jurnal Pengabdian Kesehatan Komunitas } \\
\text { (Journal of Community Health Service) }\end{array}$ \\
\hline \\
\hline
\end{tabular}

\title{
Konseling Kenali Gejala Dan Jauhi Perilaku Berisiko Penyakit Hipertensi Di Masyarakat Rt 05 Rw 12 Kelurahan Tangkerang Selatan Kota Pekanbaru Tahun 2020
}

\section{Yuyun Priwahyuni 1, Christine Vita Gloria ${ }^{2}$, Agus Alamsyah 3, Ikhtiyaruddin 3 , ${ }^{123}$ Prodi Kesehatan Masyarakat, STIKes Hang Tuah Pekanbaru email: yuyun.priwahyuni@gmail.com ${ }^{1}$}

\begin{tabular}{|c|c|}
\hline Histori artikel & Abstrak \\
\hline $\begin{array}{l}\text { Received: } \\
\text { 28-05-2021 } \\
\\
\text { Accepted: } \\
\text { 28-05-2021 } \\
\\
\text { Published: } \\
\text { 28-05-2021 }\end{array}$ & $\begin{array}{l}\text { Tekanan darah adalah suatu tekanan yang terdapat didalam } \\
\text { pembuluh darah yang terjadi saat jantung memompakan darah } \\
\text { keseluruh tubuh. Jika tekanan darah kurang dari } 120 / 80 \text { mmHg } \\
\text { maka dalam kondisi normal. Hipertensi terjadi jika tekanan darah } \\
\text { sistolik/diastoliknya melebihi } 140 / 90 \text { mmHg. Penyebab hipertensi } \\
\text { dibagi menjadi dua golongan yaitu; ;a) Hipertensi Primer Eesensial } \\
\text { merupakan hipertensi yang memiliki beberapa } \\
\text { kemungkinan penyebabnya; b) Hipertensi sekunder merupakan } \\
\text { hipertensi yang disebabkan karena gangguan pembuluh darah atau } \\
\text { organ tubuh tertentu, seperti ginjal, kelenjar adrenalin, dan aorta. } \\
\text { Tujuan PKM adalah untuk meningkatkan pengetahuan dan } \\
\text { pemahaman masyarakat bagaimana mengenali gejala dan perilaku } \\
\text { beresiko penyakit hipertensi. Metode PKM berupa konseling dan } \\
\text { pendidikan kesehatan tentang kenali gejala dan perilaku beresiko } \\
\text { penyakit hipertensi, sasaran PKM masyarakat di RT 05 RW } 12 \\
\text { Kelurahan Tangkerang Selatan Kota Pekanbaru. Kegiatan } \\
\text { dilaksanakan pada hari Kamis } 10 \text { September sampai dengan } \\
\text { tanggal } 19 \text { September } 2020 \text {. Hasil kegiatan PKM didapat bahwa } \\
\text { dari } 20 \text { masyarakat yang mengikuti kegiatan tersebut, } 70 \% \\
\text { masyarakat mengetahui dan dapat menyebutkan mengenai tentang } \\
\text { penyakit hipertensi terutama masyarakat sudah dapat mengenali } \\
\text { gejala penyakit hipertensi dan perilaku yang beresiko yang dapat } \\
\text { menyebabkan penyakit hipertensi. Kegiatan konseling dan } \\
\text { pendidikan kesehatan tentang kenali gejala dan perilaku beresiko } \\
\text { penyakit hipertensi sangat efektif dilaksanakan pada masyarakat. } \\
\text { Kepada pihak-pihak yang terkait seperti perangkat RT } 05 \text { RW } 12 \\
\text { Kelurahan Tangkerang Selatan untuk dapat berkoordinasi dengan } \\
\text { pihak puskesmas setempat agar dapat mengagendakan kegiatan } \\
\text { seperti ini secara rutin, agar dapat memberikan pengetahuan } \\
\text { kepada masyarakat tentang kenali gejala dan perilaku beresiko dari } \\
\text { penyakit hipertensi sehingga penyakit ini dapat dikendalikan. }\end{array}$ \\
\hline
\end{tabular}




\section{Kata Kunci : Penyakit Hipertensi, RT 05 RW 12 Tangkerang Selatan}

Blood pressure is the pressure contained in the blood vessels that occurs when the heart pumps blood throughout the body. If the blood pressure is less than $120 / 80 \mathrm{mmHg}$ it is under normal conditions. Hypertension occurs when the systolic / diastolic blood pressure exceeds 140/90 $\mathrm{mmHg}$. The causes of hypertension are divided into two groups, namely: a) Essential Primary Hypertension is hypertension which has several possible causes; b) Secondary hypertension is hypertension caused by disturbances in blood vessels or certain organs, such as the kidneys, adrenal glands, and aorta. The purpose of PKM is to increase public knowledge and understanding of how to recognize symptoms and behaviors at risk of hypertension. The PKM method is in the form of counseling and health education on identifying symptoms and behaviors at risk of hypertension, targeting community PKM in RT 05 RW 12, Tangkerang Selatan District, Pekanbaru City. Activities will be held on Thursday, September 10 to September 19, 2020. The results of the PKM activities showed that of the 20 people who participated in the activity, $70 \%$ of the people knew and could mention about hypertension, especially the community was able to recognize the symptoms of hypertension and risky behavior that could cause hypertension. Health education and counseling activities on identifying symptoms and behaviors at risk of hypertension are very effective in the community. To related parties such as RT $05 R W 12$ Tangkerang Selatan District to be able to coordinate with the local health center so that they can schedule activities like this on a regular basis, in order to provide knowledge to the public about recognizing symptoms and risky behavior from hypertension so that this disease can controlled.

Keywords : Keywords: Hypertension, RT 05 RW 12 Tangkerang Selatan

\section{PENDAHULUAN}

Peningkatan atau penurunan pada tekanan darah akan mempengaruhi homeostatis (keseimbangan) di dalam tubuh. Gangguan pada tekanan darah yang dapat terjadi, yaitu tekanan darah tinggi (hipertensi) dan tekanan darah rendah (hipotensi). Penyakit tekanan darah tinggi dulunya dianggap sebagai penyakit yang hanya diderita oleh orang dari kalangan atas saja yang memiliki gaya hidup modern, namun saat ini semua orang sangat berisiko tinggi terkena penyakit tekanan darah tinggi. Tekanan darah rendah juga merupakan masalah kesehatan namun penyakit darah tinggi selalu menjadi faktor risiko dari penyakit yang 
berkaitan dengan sisetem kardiovaskuler seperti penyakit jantung koroner (Anies, 2006). Menurut JNC VII 2003, klasifikasi hipertensi yaitu Normal sistol $\leq 120 \mathrm{mmHg}$ dengan diastol $80 \mathrm{mmHg}$, Pre Hipertensi sistol 120-130 mmHg dengan diastol 80-89 mmHg, Hipertensi Stage 1 sistol 140-159 mmHg dengan diastol 90-99 mmHg, Hipertensi Stage 2 sistol 160 atau >160 $\mathrm{mmHg}$ dengan diastol 100->100 mmHg.

Data World Health Organization (WHO) 2015 menunjukkan sekitar 1,13 miliar orang di dunia menderita hipertensi. Artinya, 1 dari 3 orang di dunia terdiagnosis menderita hipertensi, hanya $36,8 \%$ di antaranya yang minum obat. Jumlah penderita hipertensi di dunia terus meningkat setiap tahunnya, diperkirakan pada 2025 akan ada 1,5 miliar orang yang terkena hipertensi. Diperkirakan juga setiap tahun ada 9,4 juta orang meninggal akibat hipertensi dan komplikasi (WHO, 2015).

Berdasarkan dari data Riskesdas tahun 2018 hipertensi mengalami peningkatan dari (25,8\%) pada tahun 2013 menjadi (34,1\%). Pravelensi tertinggi terjadi di Kalimantan Selatan $(41,1 \%)$ dan yang terendah di Papua (22,2\%) sedangkan di Riau (29,2\%) (Riskesda, 2018). Sementara itu, data Survei Indikator Kesehatan Nasional (Sirkesnas) tahun 2016 adanya kenaikan persentase penduduk yang mengidap hipertensi menjadi 32,4 persen (Riskesdas, 2018).

Angka Kejadian Tekanan Darah Tinggi dari Dinas Kesehatan Kota Pekanbaru Hipertensi pada tahun 2015 ada 36.476 kasus (59\%). Tahun 2016 angka kejadian tekanan darah tinggi, yaitu 35.419 kasus (55\%). Sedangkan di Tahun 2017 angka kejadian tekanan darah tinggi yaitu 839 kasus (39\%). Dari data tersebut dari tahun 2015 sampai tahun 2017 penyakit tekanan darah tinggi selalu jadi di urutan pertama di sepuluh Penyakit Tidak Menular.

Berdasarkan hasil observasi dan survei data di lapangan yaitu di RT 05 RW 12 Kelurahan Tangkerang Selatan penyakit hipertensi masih merupakan penyakit yang banyak diderita oleh masyarakat, dari 10 orang yang diwawancarai didapatkan $70 \%$ mengalami penyakit hipertensi yang tidak terkontrol. Pengabdian kepada masyarakat ini bertujuan untuk memberikan pendidikan kesehatan dan pengetahuan tentang kenali gejala dan perilaku beresiko penakit hipertensi kepada masyarakat RT 05 RW 12 Kelurahan Tangkerang Selatan Kota Pekanbaru dengan metode konseling.

\section{HASIL DAN PEMBAHASAN}

Kegiatan Pengabdian Masyarakat dengan metode konseling kesehatan kenali gejala dan perilaku beresiko penyakit hipertensi pada masyarakat dilaksanakan di RT 05 RW 12 Kelurahan Tangkerang Selatan Kota Pekanbaru. Kegiatan diikuti oleh masyarakat yang 
berjumlah 20 orang, kegiatan dilaksanakan pada hari Kamis 10 September sampai dengan tanggal 19 September 2020 .

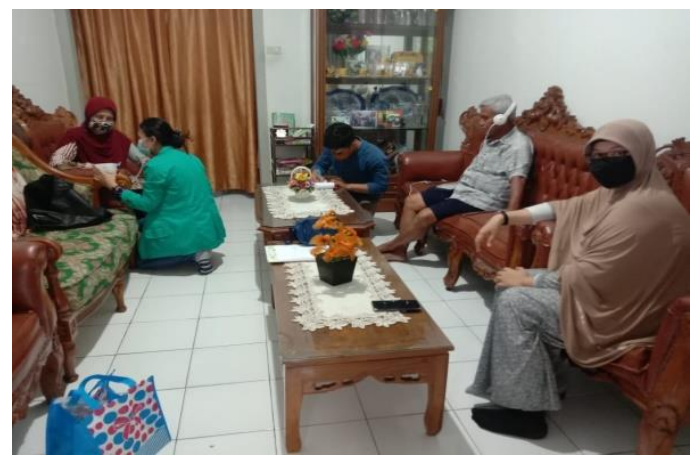

Gambar 1. Kegiatan Pengabdian Masyarakat

Bentuk kegiatan pengabdian yang dilaksanakan adalah konseling dan pendidikan kesehatan tentang kenali gejala dan perilaku beresiko penyakit hipertensi. Konseling dan pendidikan kesehatan tentang kenali gejala dan erilaku beresiko penyakit hipertensi dilakukan oleh para pengabdi dan dibantu oleh para mahasiswa/i STIKes Hang Tuah Pekanbaru Semester 7. Sebelum para peserta yakni masyarakat tersebut diberikan penjelasan tentang hepatitis, sejumlah masyarakat diberikan pertanyaan terlebih dahulu untuk mengetahui pengetahuan masyarakat terkait mengenali gejala dan perilaku beresiko penyakit hipertensi. Dari hasil tersebut dapat terlihat bahwa dari 20 masyarakat yang diberikan konseling, hanya $20 \%$ masyarakat yang mengetahui apa perilaku yang beresiko penyebab penyakit hipertensi. Setelah para pengabdi memberikan konseling materi pendidikan kesehatan tentang kenali gejala dan perilaku beresiko penyakit hipertensi, sejumlah masyarakat diberikan pertanyaan kembali mengenai penyakit hipertensi. Hasil yang didapat bahwa dari 20 masyarakat yang diberikan konseling, 70\% masyarakat mengetahui dan dapat menyebutkan mengenai penyakit penyakit hipertensi terutama masyarakat sudah dapat mengenali gejala penyakit hipertensi dan perilaku yang beresiko yang dapat menyebabkan penyakit hipertensi. Kegiatan konseling dan pendidikan kesehatan tentang kenali gejala dan perilaku beresiko penyakit hipertensi sangat efektif dilaksanakan pada masyarakat.

Pelaksanaan pengabdian masyarakat dengan metode konseling Kesehatan Kenali Gejala dan Perilaku Beresiko penyakit hipertensi pada masyarakat di RT 05 RW 12 Kelurahan Tangkerang Selatan Kota Pekanbaru merupakan salah satu bentuk kegiatan dalam meningkatkan pengetahuan dan pemahaman masyarakat dalam mengetahui penyakit 
hipertensi dan mengenali gejalanya, serta mengetahui perilaku beresiko dari penyakit hipertensi, dan penyakit hipertensi dapat dikendalikan

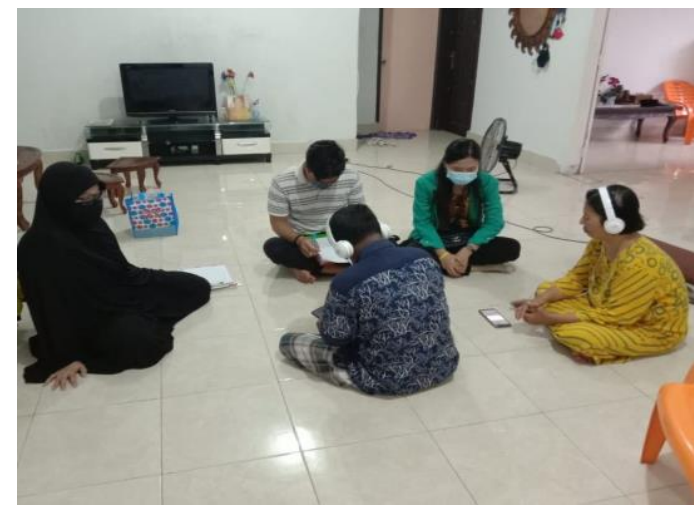

Gambar 2. konseling Kesehatan tentang penyakit hipertensi

\section{SIMPULAN}

Hasil yang dicapai melalui kegiatan Pengabdian Masyarakat tentang Kenali Gejala dan Perilaku Beresiko penyakit hipertensi adalah sebagai berikut :

1. Kegiatan Pengabdian Masyarakat dengan metode konseling Kesehatan Kenali Gejala penyakit hipertensi dan Perilaku Beresiko penyakit hipertensi pada Masyarakat RT05 RW 12 Kelurahan Tangkerang Selatan Kota Pekanbaru sangat antusias diikuti oleh masyarakat.

2. Masyarakat mendapatkan pengetahuan baru dengan diberikan konseling Kesehatan Kenali Gejala penyakit hipertensi dan Perilaku Beresiko penyakit hipertensi tersebut. Dari 20 masyarakat yang diberikan konseling Kesehatan 70\% masyarakat mengetahui dan dapat menyebutkan apa penyebab penyakit hipertensi dan pencegahan agar penyakit hipertensi dapat dikendalikan

3. Masyarakat tersebut mengatakan bahwa mereka akan lebih hati-hati lagi akan factor risiko penyakit hipertensi dan lebih menerapkan pencegahan dari penyakit hipertensi yang telah diberikan pada saat pelaksanaan pengabdian masyarakat.

\section{UCAPAN TERIMAKASIH}

Ucapan terimakasih kami sampaikan kepada Pusat Penelitian dan Pengabdian Masyarakat STIKes Hang Tuah Pekanbaru sebagai pemberi dana dalam kegiatan pengabdian masyarakat yang telah dilaksanakan pada bulan September 2020. Serta ucapan terimakasih kepada Ketua RT 05 RW 12 Kelurahan Tangkerang Selatan Kota Pekanbaru yang telah memberikan kesempatan dalam pelaksanaan pengabdian masyarakat. 


\section{DAFTAR PUSTAKA}

[1] Amiruddin, Ridwan, 2007. Hipertensi dan Faktor Resikonya Dalam Kajian Epidemiologi.Jakarta: EGC

[2]Anggraeni, Yofina, 2012. Super komplet Pengobatan Darah Tinggi. Jogjakarta: Araska.

[3]Anggara,F. H. D., \& Prayitno, N. 2013. Faktor-faktor yang berhubungan dengan tekanan darah di Puskesmas Telaga Murni Cikarang Barat. Jurnal IImiah Kesehatan, 5, (1). Diperoleh dari http://fmipa.umri.ac.id/wp-content/uploads/2016/.pdf

[4]Anies, 2006. Waspadai ancaman penyakit tidak menular. Jakarta:Gramedia

[5]B.Hurlock, Elizabet. 2014. Psikologi Perkembangan. Jakarta: PT Raja Grafindo Persada.

[6]Carey RM, Whelton PK. 2017. ACC/AHA Hypertension guideline writing committee. Prevention, detection, evaluation, and management of high blood pressure in adults: Synopsis of the 2017 American College of Cardiology/American Heart Association hypertension guideline. Ann Intern Med.

[7]Fakih, Mansour (2014). Analisis Gender \& Transformasi Sosial. Yogyakarta: Pustaka Belajar.

[8]Singalingging, G. 2011. Karakteristik Penderita Hipertensi Di Rumah Sakit Umum Herna Medan 2011. Jurnal Keperawatan Universitas Darma Agung hal 3-4 Medan.

[9]Syamsuni, 2005, Farmasetika Dasar dan Hitungan Farmasi, Penerbit Buku Kedokteran EGC, Jakarta, (online), (http:// books.google.co.id, diakses 07 Mei 2019

[10]Guyton, A.C., dan Hall, J.E. 2008. Buku Ajar Fisiologi Kedokteran. Edisi 11. Jakarta: EGC [11]JNC VII. 2003. The seventh report of the Joint National Committee on prevention, detection, evaluation, and treatment of high blood pressure. Hypertension,42:1206-52.http://hyper.ahajournals.org/cgi/content /full/42/6/1206. Diakses 12 April 2019

[12]Junaidi \& iskandar (2010). Hipertensi (Pengenalan, pencegahan, dan pengobatan). Jakarta :PT Bhuana \& Imu Populer

[13]Kartikasari, AN. 2012. Faktor Risiko Hipertensi pada Masyarakat di Desa Kabongan Kidul, Kabupaten Rembang. Jurnal Semarang FK-Undip.

[14]Kembuan, Kandou, Kaunang (2016). Hubungan Obesitas Dengan Penyakit Hipertensi Pada Pasien Poliklinik Puskesmas Touluaan Kabupaten Minahasa Tenggara. Jurnal Kesehatan Masyarakat Sam Ratulangi hal 20-21 Sulawesi Utara.

[15]Kurniadi, H. (2014). Stop! gejala penyakit jantung koroner, kolesterol tinggi, diabetes mellitus, hipertensi. Yogyakarta: Istana Media.

[16]Kowalak, J.P. (2011). Buku ajar patofisiologi.Jakarta:EGCKozie, et al .2009. Buku ajar praktik keperawatan klinis. Jakarta: EGC

Martha, Karnia. 2012. Panduan Cerdas Mengatasi Hipertensi. Jogyakarta: Araska.

[17]Miller, C., 2010. Factors Affecting Blood Pressure and Heart Rate. Available from: http://www.livestrong.com/article/196479-factors-affecting-blood-pressure-heart-rate/. Diakses 14 April 2019

[18]Nurrahmani, U. (2012), Stop! Hipertensi. Jakarta: Familia

[19]Notoatmodjo, S.(2010). Metodologi penelitian kesehatan. Jakarta: Rineka Cipta

[20]Palmer A and William, B. 2007. Simple Guide Tekanan Darah Tinggi. Alih bahasa dr Elizabeth Yasmine. Editor Rina Astikawati ,Amalia Safitri. Jakarta : Erlangga; 2007

[21]Kemenkes RI. (2018). Laporan hasil riset kesehatan dasar (RISKESDAS) Provinsi Riau. Badan penelitian dan pengembangan kesehatan Kementrian kesehatan RI.

[22]Rusdi (2009).Awas!bisa mati cepat akibat Hipertensi dan Diabetes.Jogjakarta : Power Books (IHDINA) 
[23]Santoso, Djoko (2010). Membonsai Hipertensi Surabaya: Jaring pena Sherwood, L. (2011). Fisiologi manusia dari sel ke sistem. Eds 6. Jakarta: EGC

[24]Sutanto, 2010. Cekal (Cegah dan Tangkal) Penyakit Modern (Hipertensi, Stroke, Jantung, Kolesterol, dan Diabetes).Yogyakarta:Andi.

[25]Syaifuddin. (2012). Anatomi fisisologi: kurikulum berbasis kompetensi untuk keperawatan dan kebidanan. Eds.4. Jakarta: EGC

[26]Triyanto. Endang. (2014). Pelayanan Keperawatan Bagi Penderita Hipertensi Secara Terpadu Yogyakarta : GRAHAM ILMU

[27]Townsend, MC. (2010). Diagnosis Keperawatan Psikiatri Rencana Asuhan \&Medikasi Psikotropik. Jakarta : EGC

[28]Who (2015). World health stastik. Diperoleh dari http://www.who.int/gho/publication/world health statistics/2015/en/. Diakses 22 April 2019

[29]Widjadja, R. (2009). Penyakit kronis:Tindakan, pencegahan, pengobatan secara medis maupun tradisional. Jakarta: Bee Media Indonesia. 